\title{
Regime Shift Identification of Runoff and Sediment Loads in the Yellow River Basin, China
}

Fei Wang ${ }^{1,2, *}$, Guangju Zhao ${ }^{1,2}$, Xingmin Mu ${ }^{1,2}$, Peng Gao ${ }^{1,2}$ and Wenyi Sun ${ }^{1,2}$

1 Institute of Soil and Water Conservation, Northwest A\&F University, 26 Xinong Road, Yangling 712100, Shaanxi Province, China; E-Mails: gjzhao@ms.iswc.ac.cn (G.Z.); xmmu@ms.iswc.ac.cn (X.M.); gaopeng@ms.iswc.ac.cn (P.G.); sunwy@1reis.ac.cn (W.S.)

2 Institute of Soil and Water Conservation, Chinese Academy of Sciences \& Ministry of Water Resources, 26 Xinong Road, Yangling 712100, Shaanxi Province, China

* Author to whom correspondence should be addressed; E-Mail: wafe@ms.iswc.ac.cn; Tel.: +86-29-8701-9829; Fax: +86-29-8701-2411.

External Editor: Clelia Luisa Marti

Received: 25 July 2014; in revised form: 23 September 2014 / Accepted: 28 September 2014 / Published: 13 October 2014

\begin{abstract}
Runoff and sediment loads have exhibited significant changes over the past six decades in the Yellow River Basin, China. The current study evaluates the changing trends and regime shifts in runoff and sediment loads at both the annual and monthly time scales. The associated spatial and temporal variations are analyzed by a sequential $t$-test analysis of the regime shifts (STARS) approach and the "breaks for additive seasonal and trend" (BFAST) model using hydrological data at eight stations from the 1950s to 2011. Both runoff and sediment loads exhibit significant declines $(p<0.05)$, except in the upper reaches of the river near the Tangnaihai station. The regime shifts detected by the STARS approach are not completely consistent with the results from the BFAST method. In most cases, the regime shifts occurred in 1969 and 1986, due to the construction of large reservoirs. Climate change and other human activities, such as large-scale soil and water conservation measures, can result in abrupt changes in hydrological series at some stations. The trapping effects of reservoirs not only cause regime shifts of runoff and sediment loads, but also adjust their inter-annual and seasonal distributions. Various soil and water conservation measures are responsible for the significant reduction in runoff and sediment loads in the mid-lower reaches of the Yellow River Basin. In addition, water withdrawals from both river runoff and ground water play a critical role in the changing trends in runoff
\end{abstract}


and indirectly alter the sediment loads. The findings provide a good reference for the effective promotion of climate change adaptation, water resources planning and river basin management.

Keywords: Yellow River; runoff; sediment load; trends; regime shift; human activities

\section{Introduction}

Climate changes combined with intensive human activities, such as land use/cover changes, soil and water conservation measures and reservoir construction, result in massive changes in the hydrological regime and river systems. A majority of the world's rivers have suffered a series of water quality and water quantity problems, which are predominantly attributed to climate changes and human disturbances [1-3]. Thus, assessing the changes in hydrological regimes and the responses to climate change and human activities is regarded as one of the most important challenges for understanding hydrologic mechanisms [4,5]; further, the assessment would help provide optimal water resources management.

Recently, attempts have been made to investigate hydrological changes in river systems and to assess their evidence, causes and mechanisms [6-8]. Ye et al. (2003) [9] systematically analyzed the changes in the Lena River streamflow and found a hydrologic regime shift toward early snowmelt, higher summer streamflow due to regional climate warming and permafrost degradation in the southern parts of Siberia. Nijssen et al. (2001) [10] assessed the hydrological sensitivity of nine large continental river basins to climate change based on climate predictions, and they found a reduction in the annual streamflow of most tropical and mid-latitude basins and increases in the annual flow volume in the high-latitude basins. Apart from climate changes, human activities have extensively altered river systems through impoundments and diversions to meet water, energy and transportation demands [11,12]. Statistics report that there are more than 45,000 dams above $15 \mathrm{~m}$ that are capable of holding back more than $6500 \mathrm{~km}^{3}$ of water throughout the world [13]. An overview of flow regulation and hydrological changes in the world's large river systems indicated that 172 out of 291 rivers are affected by dams, and the catchments experienced higher irrigation pressure and more economic activities compared with unaffected catchments [14]. This was also confirmed by [13], who provided global estimates of the seasonal sediment flux based on 217 rivers with good observation data. According to the study, large reservoirs trapped $20 \%$ of the global sediment flux and small reservoirs trapped another $6 \%$.

In recent decades, because of climate change and rapid population growth, changes in hydrological regimes are becoming increasing important, particularly in the arid and semi-arid region of western China $[15,16]$. A prominent example of a semi-arid ecosystem in China is the Yellow River, which exhibits significant changes in both runoff and sediment loads. The Yellow River is the second largest river in China, and it plays an important role in the development of the local economy and society. The annual runoff in the basin accounts for only $2 \%$ of the total runoff in China; however, it is the major freshwater source for 110 million people, and it supplies the water for $15 \%$ of the irrigated area [17]. Furthermore, the water resources vary greatly at spatial and temporal scales, due to the large extent of 
the river basin. However, the Yellow River is famous for its extremely concentrated sediment flow. The suspended sediment concentration may exceed $500 \mathrm{~kg} \cdot \mathrm{m}^{-3}$ during the flood period, and it can reach $1000 \mathrm{~kg} \cdot \mathrm{m}^{-3}$ in some tributaries [18]. Large amounts of sediment are deposited in the flat alluvial plain in the downstream reaches; as a result, the river beds are elevated above the ground by as much as $10 \mathrm{~m}$ (or higher) in some segments. Over thousands of years, the Yellow River Basin has suffered from catastrophic floods and droughts, which have led to tremendous losses of life and property.

Recent studies have found that the decrease in precipitation and increase in agricultural and industrial water demand have resulted in significant declines in both runoff and sediment loads in the Yellow River [15,19,20]. Further investigations in the headwater catchments of the Yellow River Basin show no significant trends in the runoff or sediment loads from 1956 to 2001 [21], while the runoff and sediment loads in the middle-lower reaches of the Yellow River have declined significantly since the 1970s [11,22-24]. An illustrative example at the Lijin station $\left(751,869 \mathrm{~km}^{2}\right)$ suggests that the average annual runoff was $33.1 \mathrm{~km}^{3}(42.35 \mathrm{~mm})$ between 1950 and 2000 , but it decreased to $15.8 \mathrm{~km}^{3}$ (20.22 $\mathrm{mm}$ ) between 2001 and 2011. The significant reduction has resulted in the severe intensification of water stress in the middle-lower reaches of the basin [13,23,25-27].

Variations in hydrological systems require trend analysis and regime shift detection. By definition, a trend is likely to continue into the future. A hydrological regime shift means that the river system changes from one regime to another, and the state has been altered by an updated regime [28]. In the Yellow River Basin, numerous studies have investigated the spatial and temporal trends in runoff and sediment loads [22,23]. However, few studies have analyzed the changes in the hydrological regime of the Yellow River Basin, including the possible causes and triggering mechanisms. Therefore, the objectives of this study are to: (1) examine whether the hydrological regime shift occurred due to the significant decline in runoff and sediment loads over the past six decades; and (2) systematically analyze the causes and triggering mechanisms of hydrological variations in the Yellow River Basin.

\section{Study Area and Data}

\subsection{Study Area}

The Yellow River is the second longest river in China, with a length of $5464 \mathrm{~km}$; it is associated with a drainage area of $75.2 \times 10^{4} \mathrm{~km}^{2}$. The river begins in the Tibetan Plateau, meanders through the northern semiarid region, crosses the Loess Plateau, passes through the North China Plain and, finally, discharges into the Bohai Sea (Figure 1). From the head of the river to the river mouth, the Yellow River passes over three typical landforms: the Tibetan high plateau, with elevations from 2000 to $5000 \mathrm{~m}$; the Loess Plateau, with elevations from 500 to $2000 \mathrm{~m}$; and the alluvial plain in the east [19]. In terms of the physical-geographical settings, the Yellow River Basin is divided into three sections. The upper Yellow River (3472 km long) extends from the river source to Hekou. The middle Yellow River (1206 km long) extends from Hekou to Taohuayu. Finally, the lower reaches (786 km long) are past Taohuayu (Figure 1). 
Figure 1. Location of the study area and hydrological stations.

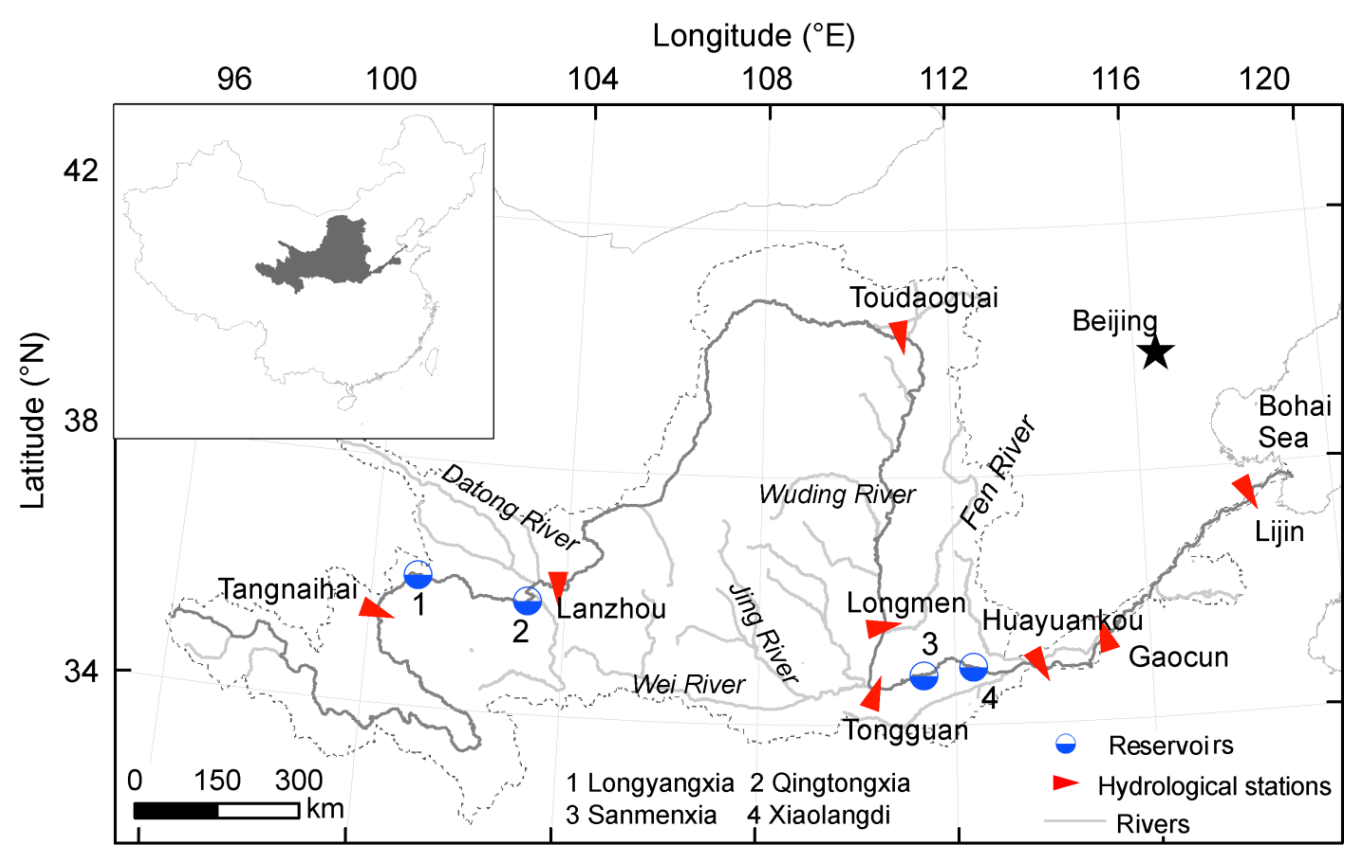

\subsection{Dataset}

The daily discharge and sediment load data prior to 1990 are collected from the Hydrological Year Book published by the Hydrological Bureau of the Ministry of Water Resources of China [29]. Since the 1990s, the annual hydrological books have not been available. The monthly data are documented in an annual report by the Hydrological Bureau and are available at the website of the Ministry of Water Resources of China [30]. According to the data availability and continuity, the monthly runoff and sediment load data at eight hydrological stations along the main stem of the Yellow River are characterized; they represent the upper, middle and lower reaches of the Yellow River. More detailed information concerning the hydrological records of these eight gauging stations is shown in Table 1.

Table 1. List of the hydrological stations used in this study.

\begin{tabular}{cccccc}
\hline Stations & Time Interval & $\begin{array}{c}\text { Annual } \\
\text { Runoff }(\mathbf{m m})\end{array}$ & $\begin{array}{c}\text { Annual Sediment } \\
\text { Load }\left(\mathbf{1 0}^{\mathbf{8}} \mathbf{~}\right)\end{array}$ & $\begin{array}{c}\text { Drainage Area } \\
\left.\mathbf{( k m}^{\mathbf{2}}\right)\end{array}$ & Location \\
\hline Tangnaihai * & $1950-2012$ & 164.87 & 0.12 & 121,972 & Upper \\
Lanzhou & $1950-2012$ & 139.07 & 0.66 & 222,551 & drainage basin \\
\hline Toudaoguai & $1950-2012$ & 58.55 & 1.03 & 367,898 & Middle \\
Longmen & $1950-2012$ & 52.78 & 6.97 & 497,552 & drainage basin \\
Tongguan & $1952-2012$ & 49.67 & 10.06 & 682,166 & \\
\hline Huayuankou & $1950-2012$ & 51.46 & 8.72 & 730,036 & Lower \\
Gaocun & $1952-2012$ & 47.64 & 7.82 & 734,146 & drainage basin \\
Lijin & $1952-2012$ & 39.79 & 7.03 & 751,869 & \\
\hline
\end{tabular}

* Sediment data are available from 1956 to 2012.

In addition, the regionally averaged annual precipitation and temperature series are interpolated from data at 78 meteorological stations. The time series of the annual precipitation and air temperature at these stations are selected from the 1950 s to 2012 according to the length, accuracy and consistency 
of the climate data. The data are provided by the National Climatic Centre (NCC) of the China Meteorological Administration (CMA). All of the data used in the study have been quality checked by the data release agencies.

\section{Methodology}

In this study, we applied a sequential $t$-test analysis of regime shifts (STARS) algorithm proposed by Rodionov [31] to detect the abrupt changes in the annual hydrological time series. The breaks for additive seasonal and trend (BFAST) model are then used to decompose the monthly runoff and sediment load series [32].

\subsection{Regime Shift Detection Using a Sequential Approach}

The STARS method can be used to detect multiple change points of a hydro-climatic time series [31]. For a given time series $x_{1}, x_{2}, \cdots, x_{n}$, the mean value of the first regime (R1) is estimated as:

$$
\bar{x}_{R 1}=\frac{\sum_{k=1}^{m} x_{k}}{m} \quad 1 \leq k \leq m
$$

where $m$ is the cut-off length of the regimes to be tested. The difference between the mean value of a new regime (R2) and the current regime (R1) can be estimated according to the Student's $t$-test:

$$
\varphi=\bar{x}_{R 2}-\bar{x}_{R 1}=t \sqrt{2 \delta_{m}^{2} / m}
$$

where $t$ is the value of the $t$-distribution with $2 m-2$ degrees of freedom at a probability level $p . \delta_{m}$ is the average standard deviation for $m$-year intervals in the time series.

A test is performed between the mean values of the subseries $x_{1}, x_{2}, \cdots, x_{m}$ and $x_{m+1}$ to determine statistically significant deviations. A year with a significant deviation is marked as a potential change point $j$, and subsequent observations are used to confirm or reject the hypothesis. The regime shift index (RSI) is estimated to confirm or reject the null hypothesis of the regime shift starting in year $j$ :

$$
R S I_{i, j}=\sum_{i=j}^{j+q} \frac{x_{i}-\left(\bar{x}_{R 1}+\varphi\right)}{m \delta_{m}} \quad q=0,1, \cdots, m-1
$$

If the RSI retains the same sign as that in year $j$, then it would increase the confidence that a shift did occur. Otherwise, the start point $j$ is false. Once a new regime is determined, it is considered the base regime. The search for the next regime shift proceeds until all the available data are evaluated.

\subsection{Time Series Decomposition}

The BFAST method, proposed by [32], integrates the iterative decomposition of a time series into trend, seasonal and noise components for detecting the changes (i.e., trends and breakpoints) within the time series. The method has been applied to detect long-term seasonal changes in satellite image time series [32]. The general model is of the form:

$$
Y_{t}=T_{t}+S_{t}+\xi_{t} \quad t=1,2, \cdots, n
$$


where $Y_{t}$ is the observed data at time $t, T_{t}$ is the trend component, $S_{t}$ is the seasonal component and the remainder component. $\xi_{t}$ denotes the remaining variation in the data beyond that in the seasonal and trend components.

Assuming that the entire time series has $l$ breakpoints $\tau_{1}, \cdots, \tau_{l}$ in the trend component $T_{t}$, then the slopes and intercepts can be estimated within each segment. The trend component can be expressed as:

$$
T_{t}=\alpha_{i}+\beta_{i} t \quad\left(\tau_{i-1}<t<\tau_{i}\right)
$$

where $i=1, \cdots, l$. The intercept $\alpha_{i}$ and slope $\beta_{i}$ can be used to assess the magnitude and direction of the abrupt change.

A harmonic model is applied to parameterize the seasonal component. The model has proven to be more suitable and robust for detecting periodical changes in seasonal time series [33]. The seasonal component is fixed between the break points in the trend component, while it can vary across break points. If the time series has $p$ seasonal break points $t_{1}, \cdots, t_{p}$, then the seasonal component $S_{t}$ can be calculated as:

$$
S_{t}=\sum_{k=1}^{k} \gamma_{k} \sin \left(\frac{2 \pi k t}{f}+\delta_{k}\right)
$$

where the parameters $\gamma_{k}$ and $\delta_{k}$, which must be estimated, represent the segment-specific amplitude and phase. The known frequency $f$ is equal to 12 for the monthly observations used here.

The moving sum (MOSUM) test based on ordinary least squares residuals is applied to detect whether one or more breakpoints occur [34]. If the test indicates a significant change $(p<0.05)$, then the break points are estimated using the method of Bai and Perron [35]. To determine the number and positions of breakpoints, the BFAST model parameters are estimated by iterating the following steps:

Step 1: If the OLS-MOSUM test indicates that break points occur in the trend component, then the number and positions of the break points in the trend component $\tau_{1}, \cdots, \tau_{l}$ are estimated from the seasonally adjusted data $Y_{t}-\hat{S}_{t}$.

Step 2: For a specific segment, the trend coefficients $\alpha_{i}$ and $\beta_{i}$ are calculated using a robust regression method based on M-estimation. The trend component for the segment can be estimated by Equation (5).

Step 3: Similarly, if the OLS-MOSUM test indicates that break points occur in the seasonal component, then the number and positions of the break points in the seasonal component $t_{1}, \cdots, t_{p}$ are estimated from the detrended data $Y_{t}-\hat{S}_{t}$.

Step 4: The parameters $\gamma_{k}$ and $\delta_{k}$ for a specific segment are calculated using a regression method based on M-estimation; then, the seasonal component in each segment can be estimated by Equation (6).

\section{Results}

\subsection{Upper Drainage Basin}

The regime shift analysis using the STARS method reveals evident break points in both the annual runoff and sediment loads at Lanzhou station (Figure 2). An abrupt decline in 1991 is examined in the runoff series. The average annual runoff at Lanzhou station is $26.5 \mathrm{~km}^{3}(119.07 \mathrm{~mm} / \mathrm{a})$ from 1992 to 
2011, which is equal to approximately $80.1 \%$ of the runoff from 1950 to 1991 . A significant increase $(p<0.05)$ is also found in 2012, which is largely attributed to much greater rainfall in this year (535.9 $\mathrm{mm}$ higher than the average annual rainfall of $454.1 \mathrm{~mm}$ ). However, the study does not discuss this break point located at the end of time series in detail, because the new regime might not occur if additional confirmational data were available. Compared with the annual runoff, the sediment load at the Lanzhou station exhibits a distinct change due to evident trapping effects from reservoirs. Clearly, an abrupt reduction is detected in 1969 in the annual sediment load. The annual average sediment load at the Lanzhou station is $1.21 \times 10^{8}$ t from 1950 to 1969 , and it decreases approximately $65 \%$ within 1969-2012 $\left(0.42 \times 10^{8} \mathrm{t}\right)$.

Compared with the Lanzhou station (Figure 2), the Tangnaihai station exhibits different abrupt changes in both the annual runoff and sediment loads. Except for the wet year of 2012, the wettest period is observed in the 1980s. Both the runoff and sediment loads show evident increases in 1981 (Table 2) and illustrate slight decreases in 1990. Furthermore, an extremely high correlation coefficient is found between the annual runoff and sediment load $\left(R^{2}=0.81\right)$. This finding may indicate synchronous changes in the runoff and sediment loads at the Tangnaihai station.

Figure 2. Regime shift detection in the annual runoff and sediment loads at the Lanzhou station. (a) Regime shift detected by STARS for annual runoff; (b) annual sediment at Lanzhou Station.
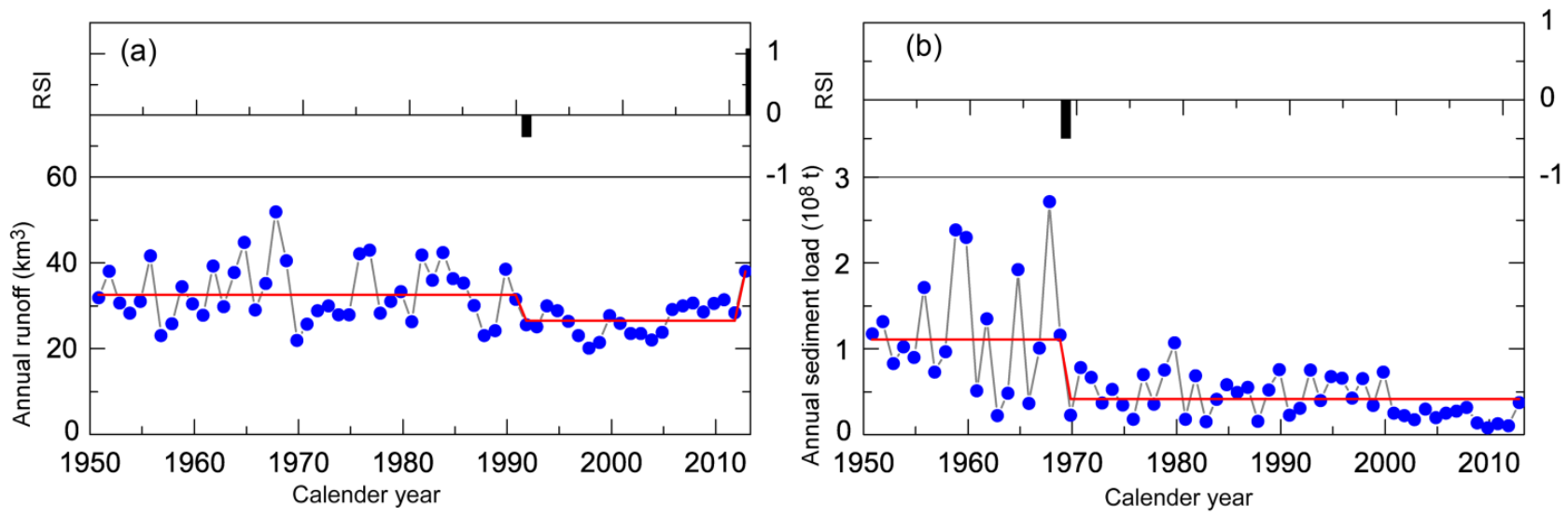

To further identify the temporal trends and regime shifts in the runoff and sediment loads, we applied the BFAST approach to decompose the monthly time series starting in the 1950s. Figure 3 illustrates the different components of the monthly runoff and sediment loads at the Lanzhou station. Figure 3a,e is the original observed values of the monthly runoff and sediment loads. The seasonal components of the runoff and sediment loads display different abrupt changes, as shown in Figure 3b,f. Abrupt decreases in the runoff and sediment loads are evident in 1969 and 1986, respectively. These trends can largely be attributed to the construction of the Liujiaxia (1969) and Longyangxia (1986) reservoirs. The fitted trend components for both the monthly runoff and sediment load demonstrate three different stages and two abrupt break points. The monthly runoff indicates evident declines in 1969 and 1986 (shown in Figure $3 \mathrm{c}$ ). However, significant increases $(p<0.01)$ at rates of $0.6 \mathrm{~km}^{3} / \mathrm{a}\left(\beta=-0.051 \mathrm{~km}^{3}\right)$ and $0.72 \mathrm{~km}^{3} / \mathrm{a}\left(\beta=-0.06 \mathrm{~km}^{3}\right)$ are detected in the components during 1950-1969 and 1970-1986, 
respectively. Consistent with runoff, the sediment loads show similar increases during 1950-1960 and 1961-1969.

Table 2. Temporal changes in the annual runoff of the Yellow River.

\begin{tabular}{ccccc}
\hline \multirow{2}{*}{ Stations } & Items & RSA & $\begin{array}{c}\text { Seasonal } \\
\text { Components }\end{array}$ & Trends (Time/Trends) \\
\hline \multirow{2}{*}{ Tangnaihai } & Runoff & 1981 & - & $1950-1981 \uparrow, 1982-2003 \downarrow, 2004-2012 \uparrow$ \\
& Sediment & 1981,1990 & - & $1950-1989 \uparrow, 1990-2012 \downarrow$ \\
\hline \multirow{2}{*}{ Lanzhou } & Runoff & 1991 & 1986 & $1950-1968 \uparrow, 1969-1985 \uparrow, 1986-2012 \uparrow$ \\
& Sediment & 1969 & 1969 & $1950-1960 \uparrow, 1961-1968 \uparrow, 1969-2012 \downarrow$ \\
\hline \multirow{2}{*}{ Toudaoguai } & Runoff & 1969,1987 & 1986 & $1950-1968 \uparrow, 1969-1985 \uparrow, 1986-2012 \downarrow$ \\
& Sediment & 1969,1988 & 1986 & $1950-1968 \uparrow, 1969-1985 \uparrow, 1986-2012 \uparrow$ \\
\hline \multirow{2}{*}{ Longmen } & Runoff & 1969,1987 & 1986 & $1950-1969 \uparrow, 1970-1986 \uparrow, 1987-2012 \downarrow$ \\
& Sediment & 1972,2005 & 1979 & - \\
\hline \multirow{2}{*}{ Tongguan } & Runoff & 1969,1991 & 1986 & $1950-1969 \uparrow, 1970-1986 \uparrow, 1987-2012 \downarrow$ \\
& Sediment & 1980,2004 & 1979 & - \\
\hline \multirow{2}{*}{ Huayuankou } & Runoff & 1969,1991 & 1986 & $1950-1969 \uparrow, 1970-1986 \uparrow, 1987-2012 \downarrow$ \\
& Sediment & $1960,1979,2000$ & 1996 & $1950-1960 \uparrow, 1961-1970 \uparrow, 1971-2012 \downarrow$ \\
\hline \multirow{2}{*}{ Gaocun } & Runoff & 1969,1991 & 1986 & $1950-1961 \downarrow, 1961-1981 \downarrow, 1982-2003 \downarrow$, \\
& Sediment & 1980,2000 & 1961,1986 & $2003-2012 \downarrow$ \\
\hline \multirow{2}{*}{ Lijin } & Runoff & 1969,1986 & 1986 & $1950-1961 \downarrow, 1962-1975 \downarrow, 1975-2003 \downarrow$, \\
& Sediment & 1969,1986 & 1960,1986 & $2003-2012 \downarrow$ \\
\hline
\end{tabular}

Figure 3. Monthly runoff and sediment load decomposition at the Lanzhou station. (a, e) Observed monthly runoff and sediment, $(\mathbf{b}, \mathbf{f})$ seasonal components of runoff and sediment decomposed by BFAST; (c, g) trends components of monthly runoff and sediment load decomposed by BFAST; $(\mathbf{d}, \mathbf{h})$ residues of runoff and sediment among observation, seasonal and trends components.
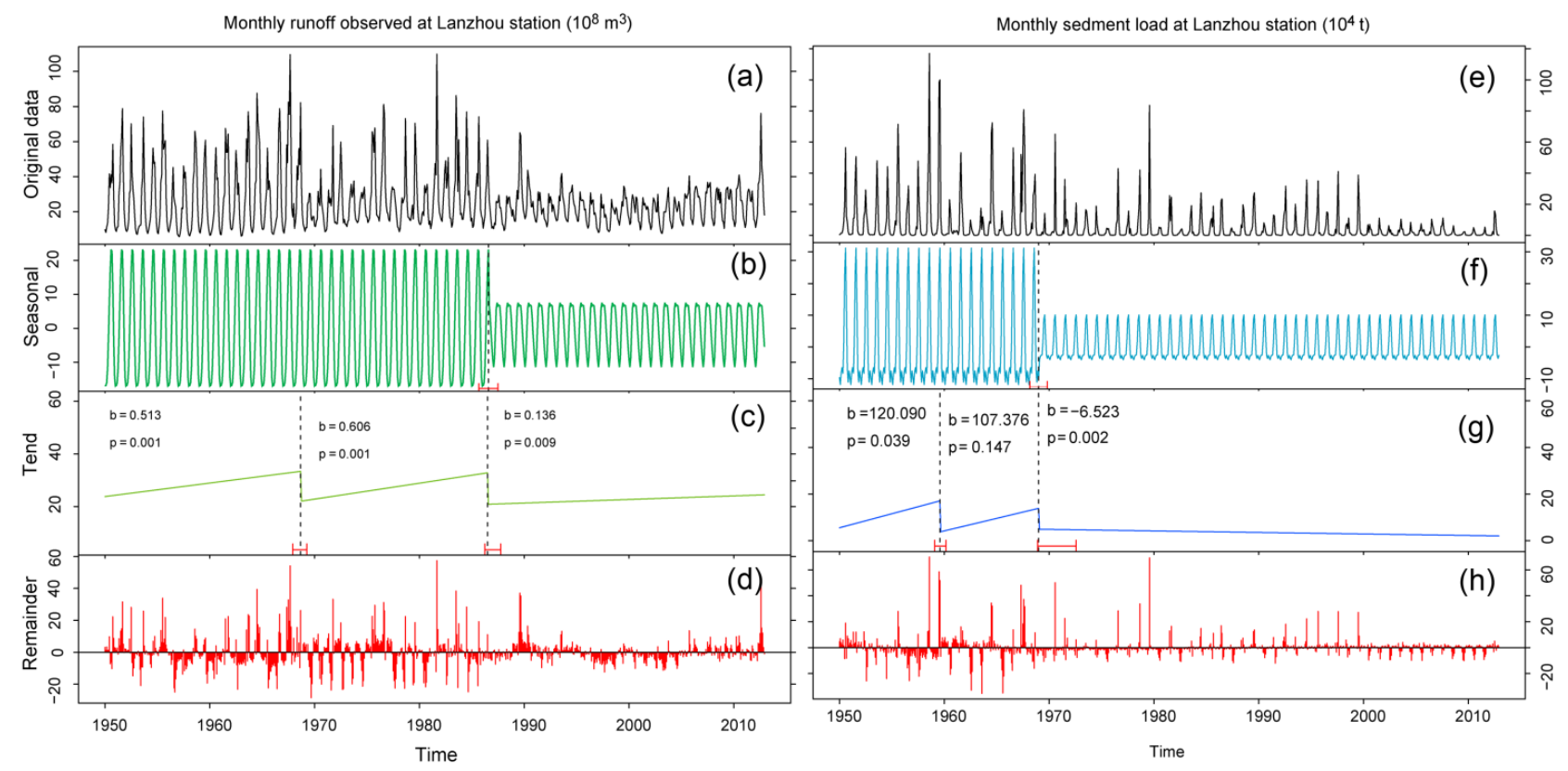
The upper reaches near the Tangnaihai station exhibit completely different changes from the Lanzhou station regarding the monthly runoff and sediment loads (see Supplementary: Figures S1 and S2). The seasonal component does not present any abrupt changes, because the station is located in the river source area. Although the water discharge shows a downward trend, the seasonal variabilities in the runoff and hydrological regime have not been altered. The trend component for the monthly runoff illustrates two break points in 1981 and 2003 (Table 2), and a significant decrease $(p<0.001)$ is apparent from 1982 to 2003 . Regarding the monthly sediment load, the trend component shows a break point in 1989. This result is similar to that detected by the STARS method.

\subsection{Middle Drainage Basin}

We selected three hydrological stations in the middle reaches of the river basin for the study: the Toudaoguai, Longmen and Tongguan stations (Figure 1). According to the analysis using the STARS method, we found evident declines in the annual runoff at the Toudaoguai station in 1969 and 1986 (Figure 4a), particularly in 1986. The average annual runoff at the Toudaoguai station is $25.2 \mathrm{~km}^{3}$ (68.50 mm/a) from 1950 to 1986 , and it decreased to $16.3 \mathrm{~km}^{3}$ (44.31 mm/a) during 1987-2012. Consistently, the sediment load illustrates significant decreases in 1969 and 1986 (Figure 4b). The average annual sediment load is $1.53 \times 10^{8} \mathrm{t}$, with high variability from 1950 to 1969 ; however, the load is only $0.44 \mathrm{t}$ from 1987 to 2012 , which is approximately $28.7 \%$ of the load in the earlier period.

Figure 4. Regime shift detection in the annual runoff and sediment loads at the Toudaoguai station. (a) Regime shift by STARS for annual runoff and (b) annual sediment at Toudaoguai Station.

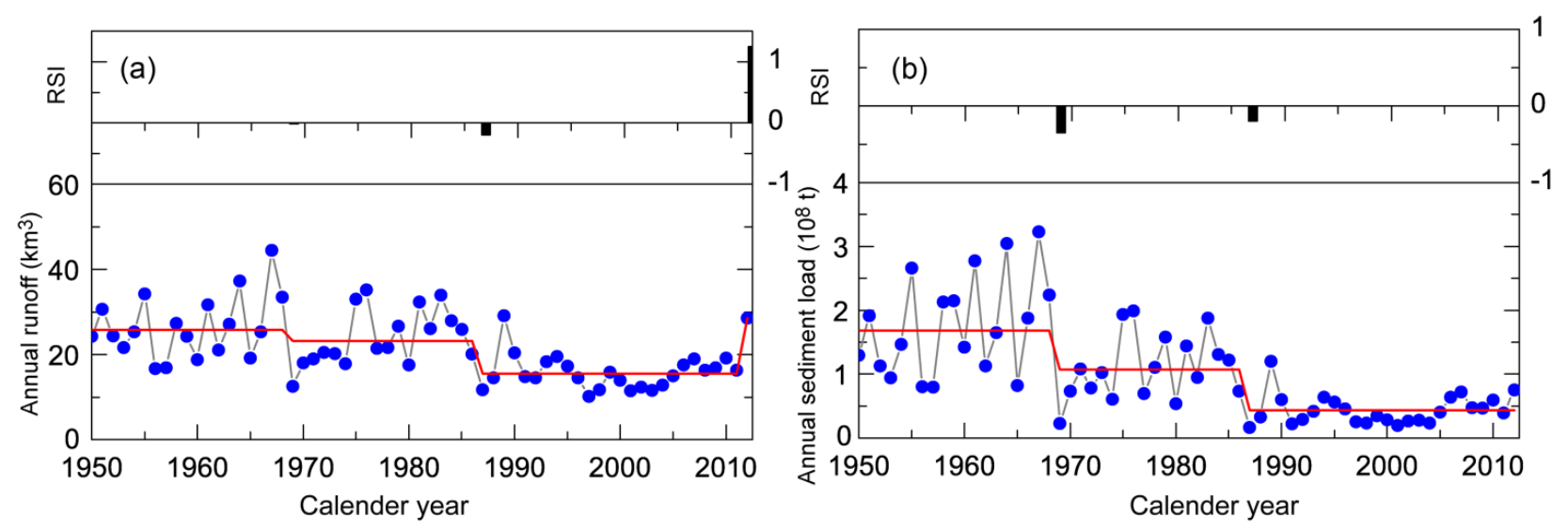

Similarly to the Toudaoguai station, the annual runoff at the Longmen and Tongguan stations demonstrates abrupt changes in 1969 and around 1986. The considerable reduction in the upstream inflow water led to abrupt changes in the annual runoff in the midstream stations. However, the annual sediment load exhibits different changes, depending on the water discharge. As shown in Table 2, the annual sediment load at the Longmen station exhibits abrupt declines in 1972 and 2004, while the break points are detected in 1980 and 2004 at the Tongguan station.

The BFAST test for the monthly runoff and sediment loads at the Toudaoguai station exhibits results similar to the Lanzhou station (Figure 5). The seasonal components of both the runoff and sediment loads indicate abrupt changes occurred in 1986, largely due to the operation of the Longyangxia 
Reservoir. Furthermore, the trend components exhibit significant increases $(p<0.05)$ during the first two periods (1950-1968 and 1969-1986).

The middle reaches of the river near the Longmen and Tongguan stations display similar changes (see Supplementary: Figures S3-S6). The seasonal components present an abrupt decline in 1986, and the trend components evidence trapping effects from the Longyangxia and Liujiaxia Reservoirs. Notably, the seasonal components of the monthly sediment load exhibit abrupt changes in 1979 at both stations, while the trend components demonstrate continuous deceases $(p<0.001)$ without any break points. According to the BFAST analysis, it can be inferred that hydrological processes are homogeneous at the Longmen and Tongguan stations, because their water discharges are predominantly controlled by the upstream inflow, and the sediment is mainly contributed by the Loess Plateau [17].

Figure 5. Monthly runoff and sediment load decomposition at the Toudaoguai station. $(\mathbf{a}, \mathbf{e})$ Observed monthly runoff and sediment load, $(\mathbf{b}, \mathbf{f})$ seasonal components of runoff and sediment decomposed by BFAST; $(\mathbf{c}, \mathbf{g})$ trends components of monthly runoff and sediment load decomposed by BFAST; $(\mathbf{d}, \mathbf{h})$ residues of runoff and sediment among observation, seasonal and trends components.
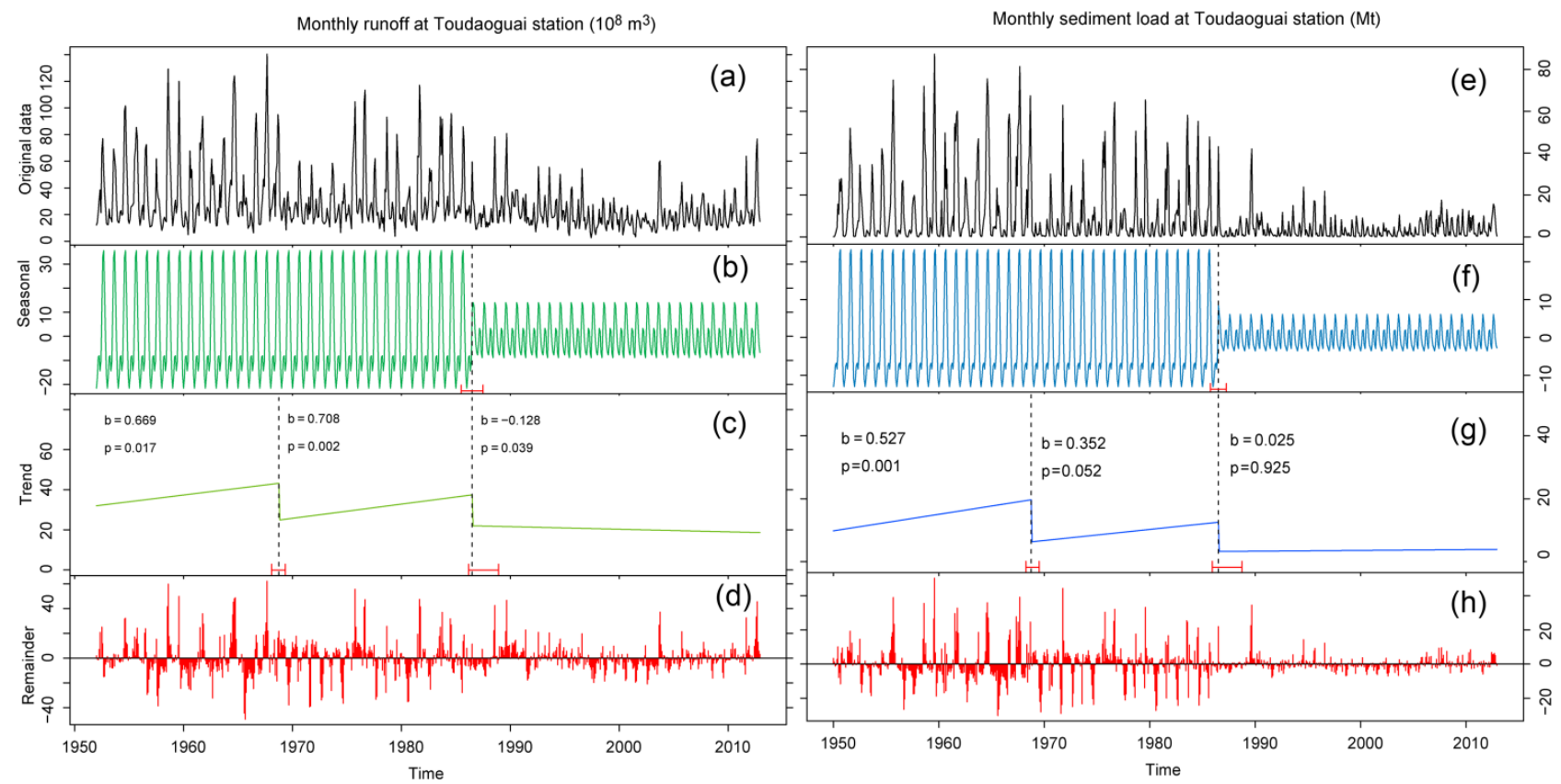

\subsection{Lower Drainage Basin}

Overall, both the runoff and sediment loads significantly decrease $(p<0.05)$ from the 1950s to 2012 at all three stations (Huayuankou, Gaocun and Lijin) in the lower basin. The Lijin station is selected as an example to display the changing trends and regime shifts in the runoff and sediment loads in the downstream Yellow River Basin. The average annual runoff at the Lijin station was $43.4 \mathrm{~km}^{3}$ in the $1950 \mathrm{~s}$, and it was reduced by approximately $50.2 \%\left(21.8 \mathrm{~km}^{3}\right)$ after 2000 . Figure 6 shows the regime shift analysis for the annual runoff and sediment loads at the Lijin station. Obviously, there are similar reductions in both the water discharge and sediment loads. Abrupt declines are found in 1969 and 
1986, similarly to the Lanzhou and Toudaoguai stations. The trapping effects of large reservoirs result in a significant reduction in the magnitudes of water and sediment loads.

Figure 6. Regime shift detection in the annual runoff and sediment loads at the Lijin station. (a) Regime shift by STARS for annual runoff and (b) annual sediment at Lijin Station.
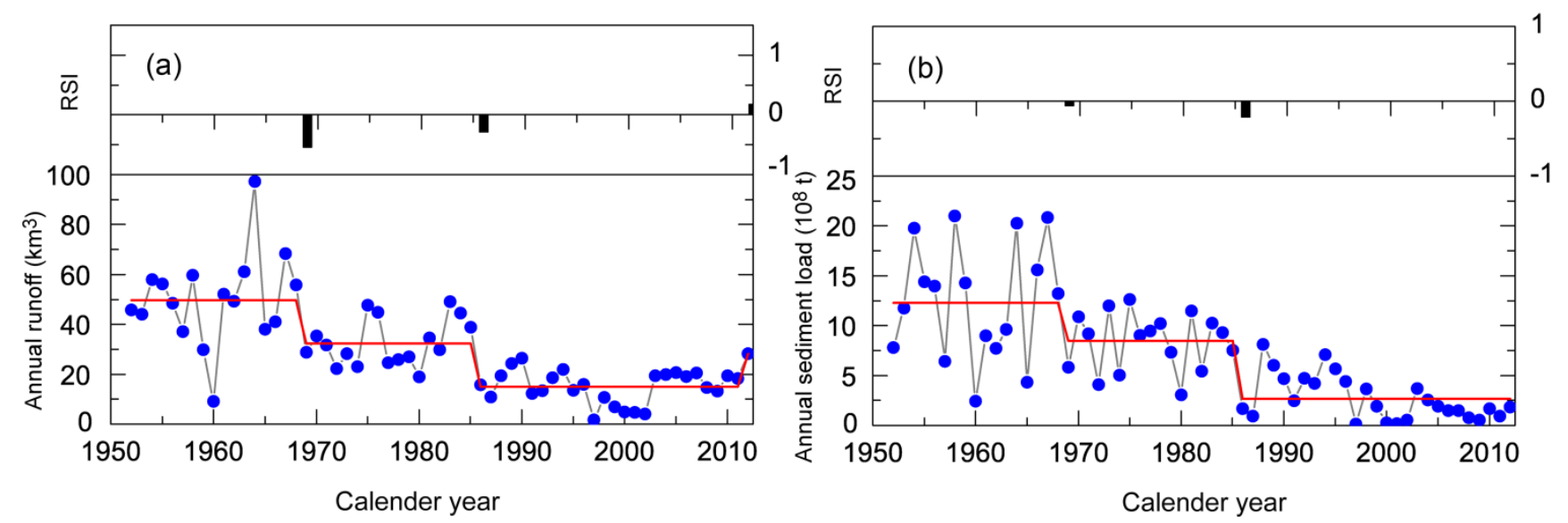

In contrast, the annual runoff and sediment loads at the Huayuankou and Gaocun stations are not completely consistent with those at the Lijin station (see Supplementary: Figure S7-S10). As listed in Table 2, we found similar changes in the annual runoff at these stations, with evident reductions in 1969 and 1991. The annual sediment load shows slightly different changes. Both stations display significant reductions around 1980 and in 2000, while the sediment load at the Huayuankou station shows an additional abrupt decline in 1960, which may largely result from the operation of the Sanmenxia Reservoir.

Figure 7 illustrates different components decomposed by the BFAST method for the monthly runoff and sediment loads at the Lijin station. The observations indicate that both the magnitude and variability are greatly reduced at the Lijin station (Figure 7a,e). Changes in the seasonal component of the monthly runoff and sediment loads are detected in 1986. Additional abrupt changes are found around 1960 due to effect of the Sanmenxia Reservoir. The trend component is more complicated in the monthly runoff than in the sediment load. Figure $7 \mathrm{c}$ demonstrates three break points in the trend component of the monthly runoff. Significant decreases $\left(\beta<-0.1 \mathrm{~km}^{3}\right)$ are detected in the first three periods $(1952-1960$, 1961-1969 and 1969-2003). In the fourth period (2004-2012), an insignificant decrease is found (slope $\beta$ of $-0.037 \mathrm{~km}^{3}$ ).

The BFAST test for the monthly runoff and sediment load at the Gaocun station exhibits similar changes to that at the Lijin station due to the low spatial variability (shown in Table 2). However, the hydrological processes at the Huayuankou station present different regimes from the above-mentioned two stations. The seasonal component in the monthly runoff shows an abrupt break in 1986, and significant increases are apparent during 1952-1969 and 1970-1986. In addition, the seasonal component of the sediment load displays an abrupt decline in 1996, and the trend component illustrates two break points in 1959 and 1969. Thus, it can be concluded that the trend component is more sensitive to the trapping effects of the reservoirs. 
Figure 7. Monthly runoff and sediment load decomposition at the Lijin station. (a, e) Observed monthly runoff and sediment, $(\mathbf{b}, \mathbf{f})$ seasonal components of runoff and sediment decomposed by BFAST; (c, g) trends components of monthly runoff and sediment load decomposed by BFAST; $(\mathbf{d}, \mathbf{h})$ residues of runoff and sediment among observation, seasonal and trends components at Lijin station.
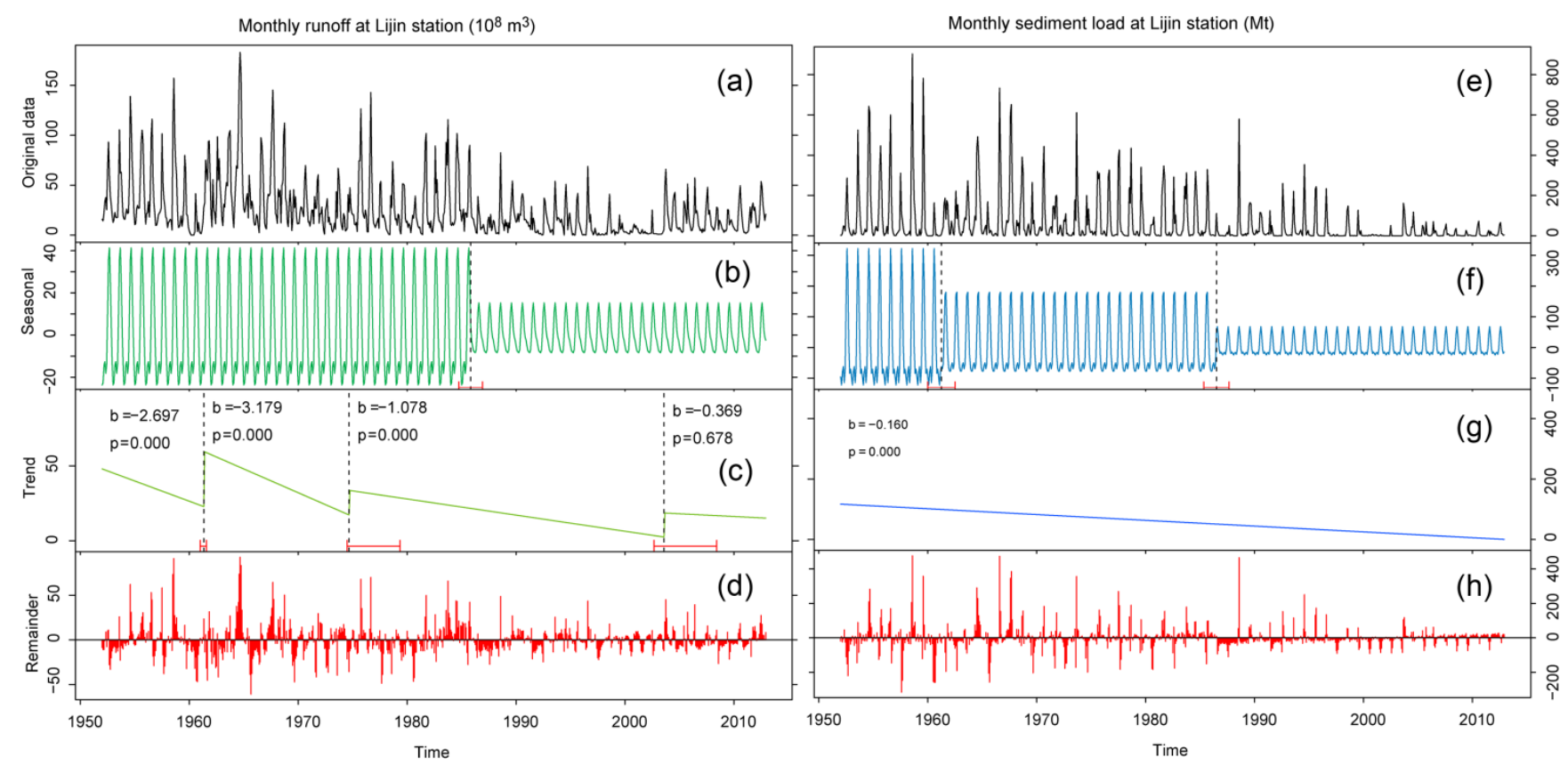

\section{Discussion}

\subsection{Break Points in River Flow and Sediment Regime}

\subsubsection{Anthropogenic Factors}

Previous studies have indicated that a hydrological regime shift may occur due to anthropogenic activities, such as dam construction or large-scale conservation measures [28,36]. Our study indicated that abrupt changes mostly occurred during large reservoir construction in the Yellow River Basin. Abrupt declines in both the runoff and sediment loads are found at the stations in the downstream region; thus, the major reservoirs along the Yellow River have substantial trapping effects. The magnitude and variability in the runoff and sediment load at these stations are reduced by the large reservoirs. Prominent examples are the Longyangxia reservoir, with a storage capacity of $27.6 \mathrm{~km}^{3}$ (1986), and the Liujiaxia reservoir, with a storage capacity of $5.7 \mathrm{~km}^{3}$ (1969) (Table 3); these reservoirs strongly altered the hydrological regime in the Yellow River Basin according to the results detected above. In the lower reaches of the river, the Sanmenxia reservoir was the first and largest reservoir (construction started in 1957 and finished in 1960), which is responsible for the significant changes (around 1960) in the sediment loads at the downstream stations (Gaocun and Lijin). A significant change in the monthly runoff at the Gaocun and Lijin stations was further detected by the BFAST test in 2003. This change may be caused by the water-sediment regulation scheme (initiated by the Yellow River Conservancy Committee in 2002), which uses the controlled release of floodwaters from the Xiaolangdi reservoir and other small reservoirs to scour the lower reaches. 
Table 3. Characteristics of large reservoirs in the Yellow River Basin.

\begin{tabular}{cccc}
\hline Reservoirs & Construction Complete & Total Storage $\left.\mathbf{( k m}^{\mathbf{3}}\right)$ & Controlled Area $\left(\mathbf{k m}^{\mathbf{2}}\right)$ \\
\hline Longyangxia & 1986 & 24.7 & 13.14 \\
Liujiaxia & 1968 & 5.7 & 18.18 \\
Xiaolangdi & 1999 & 12.7 & 69.42 \\
Sanmenxia & 1960 & 9.6 & 68.88 \\
\hline
\end{tabular}

In addition to the construction of a large number of reservoirs in the basin, soil and water conservation is an important factor that affects the water discharge and sediment loads, particularly in the mid-lower reaches of the river. This suggestion has been confirmed by our previous study via double-mass curve analysis among runoff, sediment loads and precipitation [23]. A series of soil and water conservation measures have been implemented since the late 1950s. During this period, engineering projects (e.g., terraces and dams) have been constructed, along with the implementation of biological measures, such as reforestation and planting grass. The measures have been implemented at a variable rate over time. The changing rates were very low before the 1970s due to limited funding and undeveloped techniques, and they accelerated significantly afterward because of government support and policy [37]. The regime shift analysis appears to show that the break points in the runoff and sediment load in the late 1970s and early 1980s (e.g., Longmen, Tongguan and Gaocun) can be attributed to the soil and water conservation measures, particularly the construction of check-dams. Zhang et al. (2008) [38] has supported this hypothesis based on the timing of the abrupt change points in relation to the check dams' construction in a majority of catchments in the middle reaches. These dams were mostly built during the 1970s, and they played a critical role in trapping surface runoff and sediment, i.e., both runoff and sediment were significantly reduced.

\subsubsection{Climate Factors}

The changing trends and regime shift can be triggered by external perturbations or by internal dynamics [36]. Apart from intensive human activities, climate change may also be responsible for the regime shift in the hydrological system of the Yellow River. To identify the triggering mechanism, we first examined the variation in the climate variables, including the annual precipitation and temperature. Because of the large area of the basin, we investigated the variation in the annual precipitation and temperature within the sub-regions according to the topography, climate pattern and location of hydrological stations.

Table 4 summarizes the temporal variation in the annual precipitation and temperature in five sub-regions in the Yellow River basin over the past six decades. The results from STARS suggest that the average annual precipitation in the river source region (upstream of Tangnaihai) and in the area between Toudaoguai and Sanmenxia exhibited a regime shift. Liu et al. (2008) [39] applied the Mann-Kendall test method to annual precipitation and found abrupt changes between 1963 and 1998 at different stations. There were 14 abrupt changes from 1961 to 1970: six from 1971 to 1980, 14 from 1981 to 1990 and six from 1991 to 2000 . The abrupt changes in the annual precipitation occurred at the stations within different sections of the basin. However, they are not consistent with the runoff and sediment loads at the corresponding stations. Similarly, the abrupt changes in the average annual temperature are not in good agreement with the regime shifts in the runoff and sediment load, as 
shown in Table 2. Thus, it can be inferred that the abrupt changes in the average annual precipitation and temperature are not responsible for the regime shift in the hydrological systems.

Table 4. Variation in the annual precipitation and temperature in the Yellow River basin over the past six decades.

\begin{tabular}{ccccc}
\hline \multirow{2}{*}{ Stations } & \multicolumn{2}{c}{ RSA } & \multicolumn{2}{c}{ Linear Trends } \\
\cline { 2 - 5 } & Precipitation & Temperature & Precipitation mm/a & Temperature ${ }^{\circ} \mathbf{C} / \mathbf{a}$ \\
\hline River source & 1988,2001 & 1998 & -0.043 & 0.028 \\
Tangnaihai-Lanzhou & -- & 1997 & 0.134 & 0.042 \\
Lanzhou-Toudaoguai & -- & 1987,1997 & -0.516 & 0.057 \\
Toudaoguai-Sanmenxia & 1997 & 1997 & -1.363 & 0.042 \\
Lower reaches & -- & 1959,1994 & -0.371 & 0.032 \\
\hline
\end{tabular}

By comparing the regime shifts detected by both STARS and the BFAST method (Table 2), consistent occurrence dates are identified at times when large reservoirs or dams were built (Table 3). Similar results have also been found in the Yangtze River Basin when the Three Gorges was built, which is the largest dam in the world [28]. Anderson et al. [36] stated that the regime shifts in the ecological system normally occur when it is heavily perturbed, such as during large dam construction or extreme drought events. Therefore, we believe that large reservoir construction may be the dominant factor for the regime shifts in the Yellow River. Notably, other abrupt changes from our investigation must be further analyzed to understand the changes in the river system.

\subsection{Trends in River Flow and Sediment Regime}

\subsubsection{Anthropogenic Factors}

As mentioned, large reservoirs are largely responsible for the regime shifts in hydrological systems. The reservoirs not only redistribute the seasonal water discharge and sediment load within any given year, but also reduce the total volume of runoff in the river [40]. By 2000, there were more than 3150 registered reservoirs constructed in the Yellow River basin for electricity generation, agricultural irrigation, flood mitigation and sediment regulation [18]. It was also estimated that the surface water evaporation has increased approximately $68 \%$ due to the construction of reservoirs; as a result, runoff has decreased by $2.3 \%[40,41]$. Recent statistics indicate that an area of approximately $0.2 \times 10^{6} \mathrm{~km}^{2}$ was controlled by various soil and water conservation measures by 2006, including more than 1800 key hydraulic projects and 110,000 check-dams for gully erosion control [30]. Thus, it can undoubtedly be inferred that the large scale of soil conservation measures in the Loess Plateau resulted in significant decreases in both the runoff and sediment at the mid-lower stations (i.e., Longmen, Tongguan, Huayuankou, Gaocun and Lijin).

Increasing water demands associated with the rapid development of the regional economy and the expansion of irrigated land have led to the over-exploitation of both river runoff and groundwater [40]. According to the Yellow River Water Resources Bulletin (Table 5), the average annual withdrawal from the Yellow River is approximately $48.9 \mathrm{~km}^{3}$; surface water withdrawals account for $35.7 \mathrm{~km}^{3} / \mathrm{a}$ (73.0\%), and ground water withdrawals account for 27.0\%. The Yellow River Basin primarily has a 
semi-arid climate, and agricultural production is heavily dependent on irrigation [42]. Water consumption by agricultural irrigation is approximately $22.9 \mathrm{~km}^{3} / \mathrm{a}$, which accounts for nearly $80.0 \%$ of the entire water consumption; the industrial, urban and rural domestic sectors consume the remaining $20 \%$. From Table 5, it can be concluded that water withdrawal predominantly led to the runoff reduction in different sections of the Yellow River. However, it mainly contributed to the changing trends in the observed runoff and only indirectly contributed to the sediment load decline, with very limited influences on the regime shifts of the riverine system.

Table 5. Water withdrawal and consumption in the Yellow River Basin from 1998 to 2011.

\begin{tabular}{ccccc}
\hline Annual Mean (1998-2011) $\left(\mathbf{k m}^{\mathbf{3}} \mathbf{/ a}\right)$ & Total & Agriculture & Industry & Other \\
\hline Surface water withdrawal & 35.7 & 28.7 & 3.4 & 3.6 \\
Surface water consumption & 28.6 & 22.9 & 3.9 & 1.7 \\
Ground water withdrawal & 13.2 & 6.7 & 2.5 & 4.0 \\
Ground water consumption & 8.7 & 4.5 & 1.5 & 2.7 \\
\hline
\end{tabular}

\subsubsection{Climate Factors}

As shown in Figure 8a,b, the regional average annual precipitation shows a downward trend in the range of $-0.0043 \mathrm{~mm} / \mathrm{a}$ to $-1.363 \mathrm{~mm} / \mathrm{a}$, except for the area between the Tangnaihai and Lanzhou stations (Table 4). The increase in the annual precipitation within this region is largely caused by significantly increasing precipitation $(p<0.05)$ at the Yeniugou and Xining stations. Although the average annual precipitation is increasing $(0.134 \mathrm{~mm} / \mathrm{a}$, Figure $8 \mathrm{a})$, it is not consistent with the significant decrease in both the annual runoff and sediment load. Zhang et al. (2009) [43] stated that the effects of human activities accounted for approximately $40 \%$ of the runoff reduction, and the remaining reduction was attributed to climate change. Furthermore, human activities had less influence in the upstream area of the Tangnaihai than in the upstream area of Lanzhou station.

However, all of the regions experienced a warming period within the past six decades due to the annual temperature increase between $0.028^{\circ} \mathrm{C} / \mathrm{a}$ and $0.057^{\circ} \mathrm{C} / \mathrm{a}$ (Figure 8c,d) [17]. Zheng et al. (2007) [21] found that rising temperatures would lead to more snowmelt from permanent glaciers, which would offset the runoff reduction in the headwaters of the YRB. Zhang et al. (2004) [44] indicated that the increasing temperature decreased the maximum depth of the permafrost from 3.2 to $2.8 \mathrm{~m}$; this change would increase the soil water storage capacity and reduce the runoff. In the middle-lower reaches of the river, the increasing temperature leads to more surface and soil water evaporation, which reduces the surface runoff to a large degree [45]. Yang and Liu (2011) [46] found that potential evapotranspiration increased between $0.22 \%$ and $9.34 \%$. In the middle reaches of the YRB, a quantitative analysis demonstrated that insignificantly decreasing precipitation $(p<0.05)$ and significantly increasing temperature accounted for approximately $20 \%-30 \%$ of the decline in the water discharge, which indirectly reduced the sediment transport capacity of the rivers [47]. 
Figure 8. Plots and trend lines of the annual average precipitation and temperature in the Yellow River Basin from the 1950s to 2012. (a) Variation of annual precipitation and (c) temperature in the river source, Tangnaihai-Lanzhou and Lanzhou-Toudaoguai regions; (b) variation of annual precipitation and (d) temperature in Toudaoguai-Sanmenxia and Lower reaches regions.
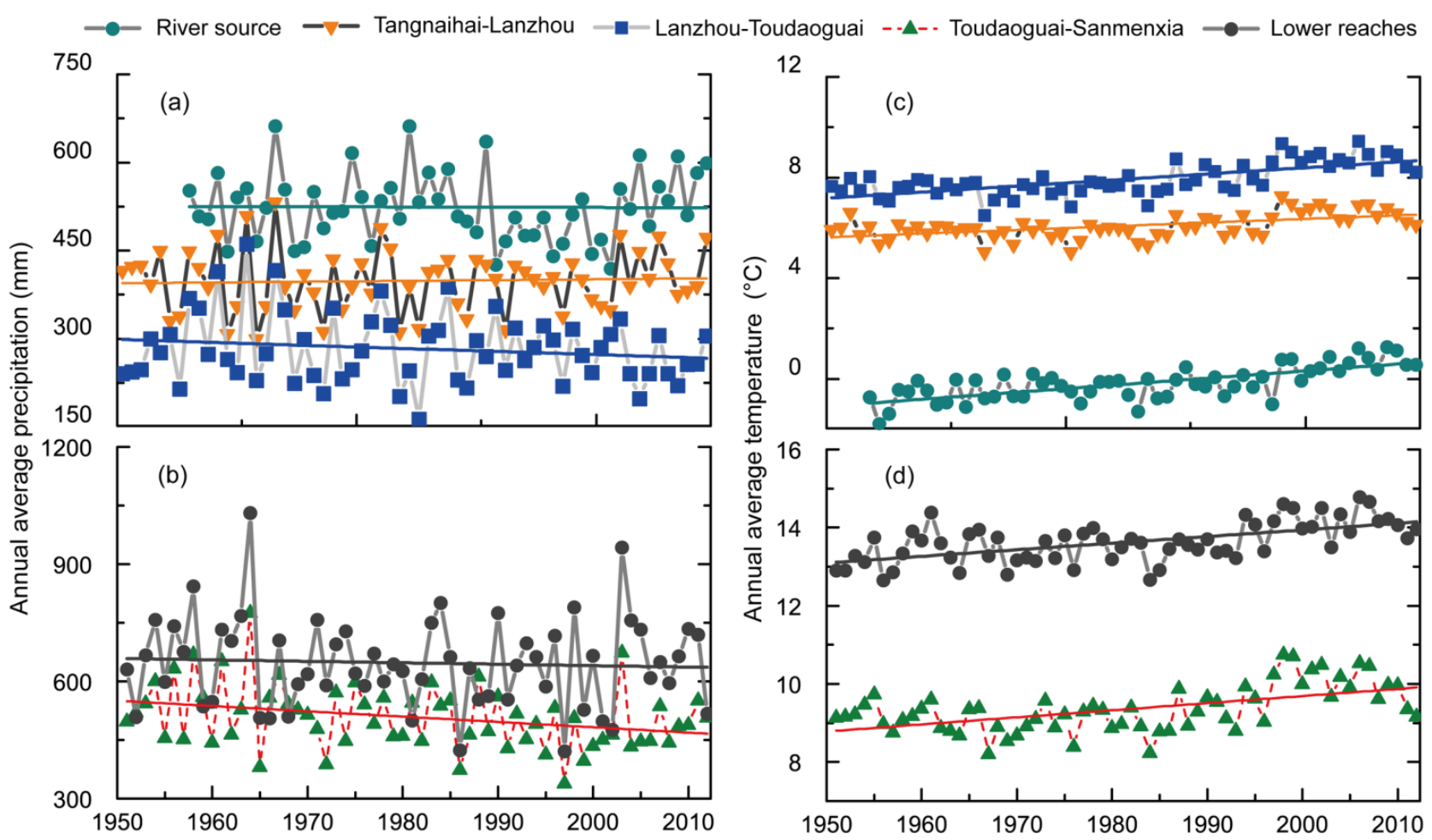

\subsection{Comparison with Other Large Rivers}

Over the past six decades, a series of hydraulic structures (e.g., dams, soil and water conservation measures) have been built for flood control, power generation, agricultural irrigation, etc. Obvious abrupt declines were found in both the annual runoff and sediment loads. This finding was similar for most of the large rivers across China. Liu et al. (2008) [48] assessed the annual runoff and sediment transport in 10 large rivers from far North China to far South China and found that the annual sediment yield decreased over the past half century. Furthermore, there has been little change in the average annual runoff; however, a dramatic decrease in the annual sediment load in the southern river has occurred. The northern rivers show significant reduction in both the annual runoff and sediment loads. Wang et al. (2011) [49] investigated the variation in the sediment flux in the five largest rivers in East and Southeast Asia (Yellow, Yangtze, Pearl, Red and Mekong). The results showed that flow regulation by dams and sediment entrapment by reservoirs, as well as human-influenced soil erosion in the river basins, sharply reduced the sediment delivered from the large river basins to the ocean. The reduction in freshwater and sediment supplies from these large river systems present severe environment challenges in the coastal ocean, including sinking deltas and declines in coastal wetland areas. For most of the Asian rivers mentioned above, the sharp drop in the sediment flux was largely attributed to large dam constructions $[48,49]$. However, this is not consistent with the Mississippi River. Meade and Moody (2010) [50] examined the causes for the decline in the suspended-sediment discharge in the Mississippi 
River, and they found that dams were not the sole cause of the reduction. Sediment trapped by the dams represented approximately half of the decrease in the sediment discharge, and other engineering activities, such as meander cutoffs, river-training structures, bank revetments and soil erosion controls, have trapped sediment. In addition, Horowitz (2010) [51] found that abrupt changes in the sediment fluxes (approximately 1993) in the Mississippi River were caused by flood rushing and not large reservoirs. The 1993 flood removed substantial amounts of sediment and eliminated a substantial local source of suspended sediment. Thus, the river becomes "sediment starved" during the course of the flood, and the river transformed from a transport-limited to a supply-limited river system.

\section{Conclusions}

This study applied two statistical approaches to investigate the changing trends and regime shifts in the runoff and sediment loads at eight hydrological stations along the Yellow River over the past six decades. Regime shifts in the annual runoff and sediment loads were analyzed using the STARS algorithm, and the BFAST method was applied to decompose the monthly runoff and sediment loads. The following conclusions are presented:

Regime shifts detected by the STARS approach are not completely consistent with the results from the BFAST method. At most stations, the runoff and sediment loads exhibit regime shifts in 1969 and 1986 that are related to the construction of large reservoirs. The trapping effects of reservoirs cause regime shifts in runoff and sediment loads and adjustments to their inter-annual and seasonal distributions. Additionally, other human activities may result in abrupt changes in the hydrological series at some stations, such as large-scale soil and water conservation measures. The abrupt changes in the annual precipitation and air temperature disagree with the regime shift in the discharge and sediment load. External perturbations, including reservoir construction and soil-water conservation, are responsible for the regime shift in the hydrological system in the middle-lower reaches of the YRB.

Both the annual runoff and sediment loads exhibit significant declines $(p<0.05)$, except at the upper reaches of the Tangnaihai station. The variation in the runoff and sediment loads in the river source area can largely be attributed to the decreasing precipitation and increasing temperature. Various soil and water conservation measures are responsible for the significant reduction in the runoff and sediment loads in the mid-lower reaches of the YRB. In addition, water withdrawals from both the river runoff and groundwater play a critical role in the runoff trends, and they indirectly alter the sediment loads. The findings provide a good reference for the effective promotion of climate change adaptation, water resources planning and river basin management.

\section{Acknowledgments}

This work was supported by the National Natural Sciences Foundation of China (Nos. 41201266, 41271295 and 41171420), the Key Research Program of the Chinese Academy of Sciences (No. KZZD-EW-04) and the Fundamental Research Funds for the Central Universities (QN2013071 and QN2011150). Moreover, the authors express their thanks to the Yellow River Conservancy Committee for providing data. 


\section{Author Contributions}

Fei Wang and Xingmin $\mathrm{Mu}$ conceived of and designed the research framework. Guangju Zhao, Peng Gao and Wenyi Sun collected and arranged the data. Fei Wang and Guangju Zhao analyzed the data and wrote the paper.

\section{Conflicts of Interest}

The authors declare no conflict of interest.

\section{References}

1. McVicar, T.R.; Li, L.; van Niel, T.G.; Zhang, L.; Li, R.; Yang, Q.; Zhang, X.; Mu, X.; Wen, Z.; Liu, W.; et al. Developing a decision support tool for china's re-vegetation program: Simulating regional impacts of afforestation on average annual streamflow in the loess plateau. For. Ecol. Manag. 2007, 251, 65-81.

2. Zhang, L.; Dawes, W.R.; Walker, G.R. Response of mean annual evapotranspiration to vegetation changes at catchment scale. Water Resour. Res. 2001, 37, 701-708.

3. Oki, T.; Kanae, S. Global hydrological cycles and world water resources. Science 2006, 313, 1068-1072.

4. Liu, Q.; Yang, Z.F. Quantitative estimation of the impact of climate change on actual evapotranspiration in the Yellow River Basin, China. J. Hydrol. 2010, 395, 226-234.

5. Xu, Z.X.; Takeuchi, K.; Ishidaira, H.; Zhang, X.W. Sustainability analysis for yellow river water resources using the system dynamics approach. Water Resour. Manag. 2002, 16, 239-261.

6. Barnett, T.P.; Pierce, D.W.; Hidalgo, H.G.; Bonfils, C.; Santer, B.D.; Das, T.; Bala, G.; Wood, A.W.; Nozawa, T.; Mirin, A.A.; et al. Human-induced changes in the hydrology of the western united states. Science 2008, 319, 1080-1083.

7. Birsan, M.V.; Molnar, P.; Burlando, P.; Pfaundler, M. Streamflow trends in Switzerland. J. Hydrol. 2005, 314, 312-329.

8. Jiang, T.; Su, B.; Hartmann, H. Temporal and spatial trends of precipitation and river flow in the Yangtze River Basin, 1961-2000. Geomorphology 2007, 85, 143-154.

9. Ye, B.S.; Yang, D.Q.; Kane, D.L. Changes in lena river streamflow hydrology: Human impacts versus natural variations. Water Resour. Res. 2003, 39, 1200.

10. Nijssen, B.; O’Donnell, G.M.; Hamlet, A.F.; Lettenmaier, D.P. Hydrologic sensitivity of global rivers to climate change. Clim. Chang. 2001, 50, 143-175.

11. Wang, H.J.; Yang, Z.S.; Saito, Y.; Liu, J.P.; Sun, X.X.; Wang, Y. Stepwise decreases of the huanghe (Yellow River) sediment load (1950-2005): Impacts of climate change and human activities. Glob. Planet Chang. 2007, 57, 331-354.

12. Milly, P.C.D.; Betancourt, J.; Falkenmark, M.; Hirsch, R.M.; Kundzewicz, Z.W.; Lettenmaier, D.P.; Stouffer, R.J. Climate change-Stationarity is dead: Whither water management? Science 2008, $319,573-574$.

13. Syvitski, J.P.M.; Vorosmarty, C.J.; Kettner, A.J.; Green, P. Impact of humans on the flux of terrestrial sediment to the global coastal ocean. Science 2005, 308, 376-380. 
14. Nilsson, C.; Reidy, C.A.; Dynesius, M.; Revenga, C. Fragmentation and flow regulation of the world's large river systems. Science 2005, 308, 405-408.

15. Giordano, M.; Zhu, Z.P.; Cai, X.M.; Hong, S.Q.; Zhang, X.C.; Xue, Y.P. Water Management in the Yellow River Basin: Background, Current Critical Issues and Future Research Needs; Comprehensive Assessment of Water Management in Agriculture Research Report 3; International Water Management Institute (IWMI): Colombo, Sri Lanka, 2004; p. 48.

16. $\mathrm{Xu}, \mathrm{J} . \mathrm{X}$. The water fluxes of the Yellow River to the sea in the past 50 years, in response to climate change and human activities. Environ. Manag. 2005, 35, 620-631.

17. Zhao, G.; Mu, X.; Wen, Z.; Wang, F.; Gao, P. Soil erosion, conservation, and eco-environment changes in the loess plateau of China. Land Degrad. Dev. 2013, 24, 499-510.

18. Zhao, G.J.; Mu, X.M.; Tian, P.; Jiao, J.Y.; Wang, F. Have conservation measures improved Yellow River health? J. Soil Water Conserv. 2013, 68, 159A-161A.

19. Yang, D.W.; Li, C.; Hu, H.P.; Lei, Z.D.; Yang, S.X.; Kusuda, T.; Koike, T.; Musiake, K. Analysis of water resources variability in the Yellow River of china during the last half century using historical data. Water Resour. Res. 2004, 40, W06502.

20. Yao, W.Y.; Xu, J.H.; Ran, D.C. Assessment of Changing Trends in Streamflow and Sediment Fluxes in the Yellow River Basin; Yellow River Conservancy Press: Zhengzhou, China, 2011. (In Chinese)

21. Zheng, H.X.; Zhang, L.; Liu, C.M.; Shao, Q.X.; Fukushima, Y. Changes in stream flow regime in headwater catchments of the Yellow River Basin since the 1950s. Hydrol. Process. 2007, 21, 886-893.

22. Fu, G.B.; Charles, S.P.; Chiew, F.H.S. A two-parameter climate elasticity of streamflow index to assess climate change effects on annual streamflow. Water Resour. Res. 2007, 43, W11419.

23. Mu, X.M.; Zhang, X.Q.; Shao, H.B.; Gao, P.; Wang, F.; Jiao, J.Y.; Zhu, J.L. Dynamic changes of sediment discharge and the influencing factors in the Yellow River, China, for the recent 90 years. Clean-Soil Air Water 2012, 40, 303-309.

24. Wang, Y.; Ding, Y.J.; Ye, B.S.; Wang, J.; Wang, J. Contributions of climate and human activities to changes in runoff of the yellow and Yangtze Rivers from 1950 to 2008. Sci. China 2013, 56, $1398-1412$.

25. Xu, J.X.; Ma, Y.X. Response of the hydrological regime of the Yellow River to the changing monsoon intensity and human activity. Hydrol. Sci. J. 2009, 54, 90-100.

26. Sato, Y.; Ma, X.Y.; Xu, J.Q.; Matsuoka, M.; Zheng, H.X.; Liu, C.M.; Fukushima, Y. Analysis of long-term water balance in the source area of the Yellow River Basin. Hydrol. Process. 2008, 22, 1618-1629.

27. Xia, C.; Pahl-Wostl, C. The development of water allocation management in the Yellow River Basin. Water Resour. Manag. 2012, 26, 3395-3414.

28. Liu, Y.B.; Wu, G.P.; Zhao, X.S. Recent declines in China's largest freshwater lake: Trend or regime shift? Environ. Res. Lett. 2013, 8, 014010.

29. YRCC (Yellow River Conservancy Committee). Hydrologic Year Books of the Yellow River; Yellow River Conservancy Press: Zhengzhou, China, 1997. 
30. Ministry of Water Resources of P.R. China (CMWR). Programming for Check Dams in the Loess Plateau; CMWR: Beijing, China, 2003; pp. 47-48.

31. Rodionov, S.N. Use of prewhitening in climate regime shift detection. Geophys. Res. Lett. 2006, 33, doi:10.1029/2006GL025904.

32. Verbesselt, J.; Hyndman, R.; Newnham, G.; Culvenor, D. Detecting trend and seasonal changes in satellite image time series. Remote Sens. Environ. 2010, 114, 106-115.

33. Verbesselt, J.; Hyndman, R.; Zeileis, A.; Culvenor, D. Phenological change detection while accounting for abrupt and gradual trends in satellite image time series. Remote Sens. Environ. 2010, 114, 2970-2980.

34. Zeileis, A. A unified approach to structural change tests based on ML scores, $F$ statistics, and OLS residuals. Econom. Rev. 2005, 24, 445-466.

35. Bai, J.S.; Perron, P. Estimating and testing linear models with multiple structural changes. Econometrica 1998, 66, 47-78.

36. Andersen, T.; Carstensen, J.; Hernandez-Garcia, E.; Duarte, C.M. Ecological thresholds and regime shifts: Approaches to identification. Trends Ecol. Evol. 2009, 24, 49-57.

37. Zhang, J.J.; Ji, W.H.; Feng, X.D. Study of Runoff and Sediment Load Changes in Wuding River Basin: Present, Causes and Future Trends. In Study of Changes in Runoff and Sediment Load in the Yellow River; Wang, G., Fan, Z., Eds.; Yellow River Water Conservancy Press: Zhengzhou, China, 2002; Volume 2, pp. 393-429.

38. Zhang, X.P.; Zhang, L.; Zhao, J.; Rustomji, P.; Hairsine, P. Responses of streamflow to changes in climate and land use/cover in the loess plateau, China. Water Resour. Res. 2008, 44, doi:10.1029/2007WR006711.

39. Liu, Q.; Yang, Z.F.; Cui, B.S. Spatial and temporal variability of annual precipitation during 1961-2006 in Yellow River Basin, China. J. Hydrol. 2008, 361, 330-338.

40. He, B.; Miao, C.Y.; Shi, W. Trend, abrupt change, and periodicity of streamflow in the mainstream of yellow river. Environ. Monit. Assess. 2013, 185, 6187-6199.

41. Liu, C.M.; Zhang, X.C. Causal analysis on actual water flow reduction in the mainstream of the Yellow River. Acta Geogr. Sin. 2004, 59, 323-330.

42. Yellow River Conservancy Commission (YRCC). Yellow River Water Resources Bulletin. Available online: http://www.Yellowriver.Gov.Cn/other/hhgb/ (accessed on 3 November 2013).

43. Zhao, F.F.; Xu, Z.X.; Zhang, L.; Zuo, D.P. Streamflow response to climate variability and human activities in the upper catchment of the Yellow River Basin. Sci. China Ser. E 2009, 52, 3249-3256.

44. Zhang, S.; Wang, Y.; Zhao, Y.; Huang, Y. Permafrost degradation and its environmental sequent in the source regions of the yellow river. J. Glaciol. Geocryol. 2004, 26, 1-6.

45. Mu, X.M.; Zhang, L.; McVicar, T.R.; Chille, B.S.; Gau, P. Analysis of the impact of conservation measures on stream flow regime in catchments of the loess plateau, China. Hydrol. Process. 2007, 21, 2124-2134.

46. Yang, Z.F.; Liu, Q. Response of streamflow to climate changes in the Yellow River Basin, China. J. Hydrometeorol. 2011, 12, 1113-1126. 
47. Zhao, G.J.; Mu, X.M.; Alex, S.; Tian, P. Temporal variation of streamflow, sediment load and their relationship in the Yellow River Basin, China. PLoS ONE 2014, 9, e91048.

48. Liu, C.; Sui, J.Y.; Wang, Z.Y. Sediment load reduction in Chinese Rivers. Int. J. Sediment. Res. 2008, 23, 44-55.

49. Wang, H.J.; Saito, Y.; Zhang, Y.; Bi, N.S.; Sun, X.X.; Yang, Z.S. Recent changes of sediment flux to the western pacific ocean from major rivers in east and southeast asia. Earth-Sci. Rev. 2011, 108, 80-100.

50. Meade, R.H.; Moody, J.A. Causes for the decline of suspended-sediment discharge in the Mississippi River system, 1940-2007. Hydrol. Process. 2010, 24, 35-49.

51. Horowitz, A.J. A quarter century of declining suspended sediment fluxes in the Mississippi River and the effect of the 1993 flood. Hydrol. Process. 2010, 24, 13-34.

(C) 2014 by the authors; licensee MDPI, Basel, Switzerland. This article is an open access article distributed under the terms and conditions of the Creative Commons Attribution license (http://creativecommons.org/licenses/by/4.0/). 